\title{
PENGARUH PENGGUNAAN RUMPON PORTABLEDAN JENIS LAMPU SETTING TERHADAP HASIL TANGKAPAN BAGAN TANCAP DI PERAIRAN TELUK PALABUHANRATU, JAWA BARAT
}

\section{The Effect of Using The Portable Fads and The Type of Lamp Setting Due to The Catch of Fixed Bagan in Pelabuhanratu Bay West Java}

\author{
Oleh : \\ Yadudin ${ }^{1}$, M. Fedi A Sondita ${ }^{1}$, Zulkarnain ${ }^{1 *}$ dan Fis Purwangka ${ }^{1}$ \\ ${ }_{1}^{1}$ Departemen Pemanfaatan Sumberdaya Perikanan, Fakultas Perikanan dan Ilmu Kelautan, \\ Institut Pertanian Bogor \\ *Korespondensi: zulkarnain_psp@yahoo.com
}

\begin{abstract}
ABSTRAK
Semakin berkembangnya teknologi, penggunaan lampu sebagai alat bantu penangkapan pada perikanan bagan di Palabuhanratu banyak mengalami perubahan, yaitu semua bagan baik bagan apung maupun bagan tancap yang sebelumnya menggunakan lampu petromaks pada saat ini sudah menggunakan lampu listrik. Jenis lampu yang digunakan pada penelitian ini adalah light emitting diode (LED) yang memiliki keunggulan hemat energi dan memiliki umur teknis yang tahan lama. Alat bantu lainnya yang sering digunakan pada perikanan tangkap adalah rumpon. Rumpon sudah lama digunakan pada perikanan tangkap sebagai alat pemikat ikan. Penggunaan rumpon pada bagan tancap bertujuan untuk mengumpulkan ikan pada siang hari sehingga pada malam hari nelayan bisa melakukan kegiatan penangkapan. Tujuan dari penelitian ini adalah: (1) Membandingkan hasil tangkapan di antara dua unit bagan yang masing-masing dilengkapi dengan 4 unit rumpon portable namun dengan jenis lampu yang berbeda, yaitu lampu LED (Bagan A) dan lampu standar (bagan B). (2) Membandingkan hasil tangkapan di antara dua unit bagan yang masing-masing dilengkapi dengan lampu standar namun dengan jumlah rumpon portable yang berbeda, yaitu 4 unit rumpon (Bagan B) dan 2 unit rumpon (Bagan C). Penelitian ini menggunakan metode experimental fishing dengan ulangan sebanyak 20 kali (trip). Uji t statistik menyimpulkan perbedaan hasil tangkapan signifikan di antara bagan A dan B untuk ikan udang rebon, layur, dan teri $(\alpha=0,05)$. Uji t statistik juga menyimpulkan perbedaan pada hasil tangkapan yang signifikan di antara bagan B dan C untuk ikan teri, tembang, layur dan udang rebon $(\alpha=0,05)$.
\end{abstract}

Kata kunci: hasil tangkapan, LED (light emitting diode), rumpon portable.

\section{ABSTRACT}

Nowadays, usage of lamps on liftnet fisheries in Palabuhanratu has experienced many changes. All liftnets, both mobile and stationary, previously used pressured kerosene lamps but now they use electric lamps. Type of lamps used in this research is light emitting diode (LED) because of its low energy consumption and more durable. Fish aggregating devices (FADs) have long been used in capture fisheries, including liftnets. Liftnets catch fish more efficiently by concentrating fish schools daytime and catch them at night fishermen by means of lights as fish attractor. The objectives of this research are (1) to compare fish catch between two liftnets equipped with 4 FADs but different in types of lamp, i.e. LED (liftnet A) and flourescent (liftnet B), (2) to compare fish catch between two lifnets equipped with flourescent lamps but different in number of FADs, i.e. 4 FADs (liftnet B) and 2 FADs (liftnet C). This research is conducted in experimental fishing approach and 
each lifftnet was operated 20 times. Statistical analysis using $t$ test concluded a signifikant difference in catcah of small shrimp, hairtail fish and anchovies $(\alpha=0,05)$ between liftnet $A$ and $B$, and a signifikant difference in catches of anchovy, sardines, hairtail fish and small shrimp between liftnet $B$ and $C(\alpha=0,05)$.

Keyword : catch, LED (light emitting diode), portable FAD.

\section{PENDAHULUAN}

Pada perikanan bagan ada beberapa alat bantu penangkapan ikan yang biasanya digunakan oleh nelayan salah satunya lampu. Lampu sudah lama digunakan dalam penangkapan ikan. Ada beberapa jenis lampu yang digunakan diantaranya petromaks, lampu neon, lampu bawah air dan LED (Light Emitting Diode). Semakin berkembangnya teknologi penggunaan lampu pada perikanan bagan di Palabuhanratu mengalami perubahan, yaitu semua bagan baik bagan apung maupun bagan tancap yang sebelumnya menggunakan lampu petromaks sekarang sudah menggunakan lampu listrik. Berbagai penelitian tentang penggunaan lampu pada perikanan bagan sudah dilakukan seperti Pada penelitian zulkarnain (2002) mengenai Studi tentang penggunaan rumpon pada bagan apung di teluk palabuhanratu, Nurdiana (2005) mengenai Iluminasi cahaya lampu pijar 25 watt pada medium udara, Siti Rohanah (2012) mengenai studi pendahuluan penggunaan lampu tabung bereflaktometer trhadap hasil tangkapan bagan apung. Pada perikanan bagan ada dua jenis lampu yang digunakan untuk menangkap ikan, yaitu lampu setting dan hauling. Lampu setting memiliki cahaya yang lebih terang digunakan untuk mengumpulkan ikan, biasanya ikan yang berkumpul adalah ikan ikan kecil yang tertarik terhadap cahaya. Lampu hauling memiliki cahaya redup atau remang remang digunakan untuk memfokuskan ikan agar mudah di tangkap. Lampu hauling digunakan setelah ikan diperkirakan sudah banyak terkumpul oleh lampu setting. Lampu setting yang digunakan pada penelitian ini adalah LED, pertimbangan penggunaan lampu LED pada penelitian ini karena lampu LED lebih tahan lama dan hemat energi, selain itu belum ada penelitian tentang lampu LED yang digunakan diperikanan bagan.

Alat bantu penangkapan lainnya yang sering digunakan pada perikanan tangkap adalah rumpon. Rumpon sudah lama dipakai dalam perikanan tangkap sebagai alat pemikat ikan. Salah satu faktor keberhasilan dari pengoperasian bagan adalah banyaknya ikan yang berkumpul di sekitar bagan. Seiring dengan ini, salah satu kendala penting yang dihadapi nelayan adalah justru ikan-ikan tersebut tidak terkonsentrasi di sekitar bagan. Kendala ini dapat ditangani dengan cara di antaranya adalah penggunaan teknologi rumpon portable. Rumpon portable akan berhasil jika pada siang hari ikan akan terkonsentrasi tetap disekitar rumpon dan pada malam hari nelayan bisa melakukan mengoperasikan bagan dengan menggunakan lampu listrik. Penggunaan rumpon pada pengoprasian penangkapan ikan telah lama dikenal oleh nelayan, baik untuk rumpon laut dangkal maupun rumpon laut dalam. Namun untuk nelayan bagan di Palabuhanratu sendiri bagan dengan rumpon adalah sesuatu yang baru dan belum pernah digunakan.

Penelitian ini bertujuan untuk melihat pengaruh lampu LED terhadap hasil tangkapan bagan dan membandingkan hasil tangkapan total tiga buah bagan tancap yang menggunakan lampu listrik dan rumpon portable serta membandingkan hasil tangkapan jenis ikan yang dominan dari tiga buah bagan tancap yang menggunakan lampu listrik dan rumpon portable.

\section{METODE PENELITIAN}

Pengumpulan data dilapangan dilaksanakan selama 2 bulan, sejak bulan Juli - Agustus 2012 yang berlokasi di Teluk Palabuhanratu Sukabumi, Jawa Barat. 
Alat dan bahan yang digunakan pada penelitian ini adalah:

1) Tiga unit bagan tancap;

(1) Bagan A dengan empat rumpon portable dan lampu LED

(2) Bagan B dengan empat rumpon portable dan lampu standard nelayan (flurescent lamp)

(3) Bagan C dengan dua rumpon dan lampu standar nelayan (flurescent lamp)

Bagan tancap sebagai tempat kegiatan operasi penangkapan ikan dengan jaring sebagai alat penangkap ikan dan lampu sebagai sumber cahaya untuk mengumpulkan ikan. Bagan tancap yang digunakan berjumlah 3 unit dengan lokasi penangkapan di Teluk Palabuhanratu, masing-masing berukuran panjang dan lebarnya $7 \mathrm{~m}$ x $7 \mathrm{~m}$ dan lokasinya di perairan dengan kedalaman 9,5 meter. Bagan tancap yang digunakan pada penelitian dapat dilihat pada Gambar 1.

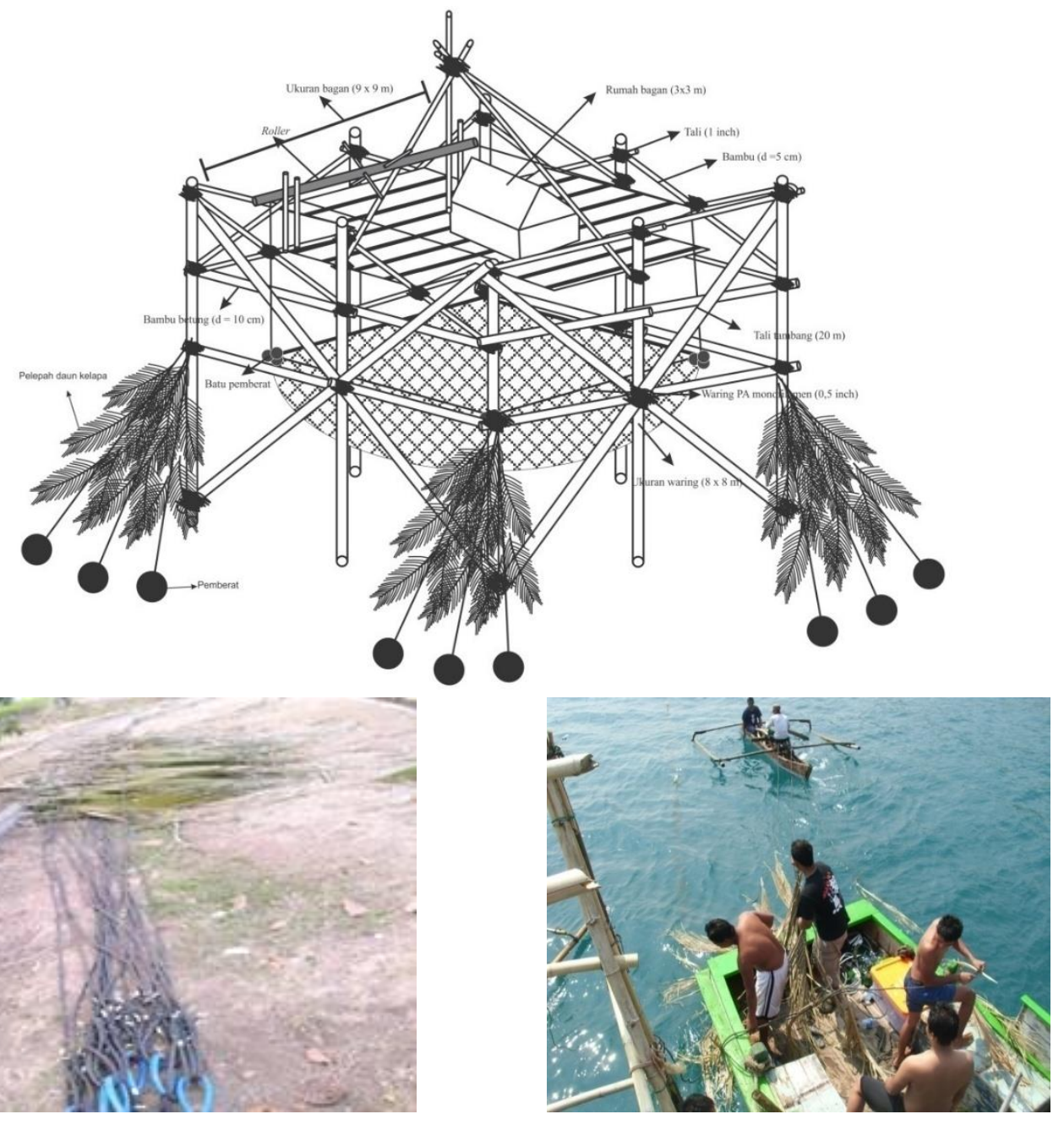

Gambar 1 Konstruksi rumpon portable yang terpasang pada bagan penelitian

2) Alat pemikat ikan

Dua jenis alat pemikat ikan digunakan secara simultan, yaitu rumpon portable dan lampu pemikat ikan; lampu tersebut terdiri dari lampu setting dan lampu hauling. Rumpon yang digunakan terbuat dari daun kelapa dan dipasang dengan jumlah berbeda untuk setiap bagan, bagan pertama (bagan A) menggunakan 4 rumpon dengan lampu LED sebagai lampu setting, bagan kedua (bagan B) menggunakan 4 rumpon dengan lampu neon sebagai lampu setting, bagan ke tiga (bagan C) menggunakan 2 rumpon dengan lampu neon sebagai lampu setting. 

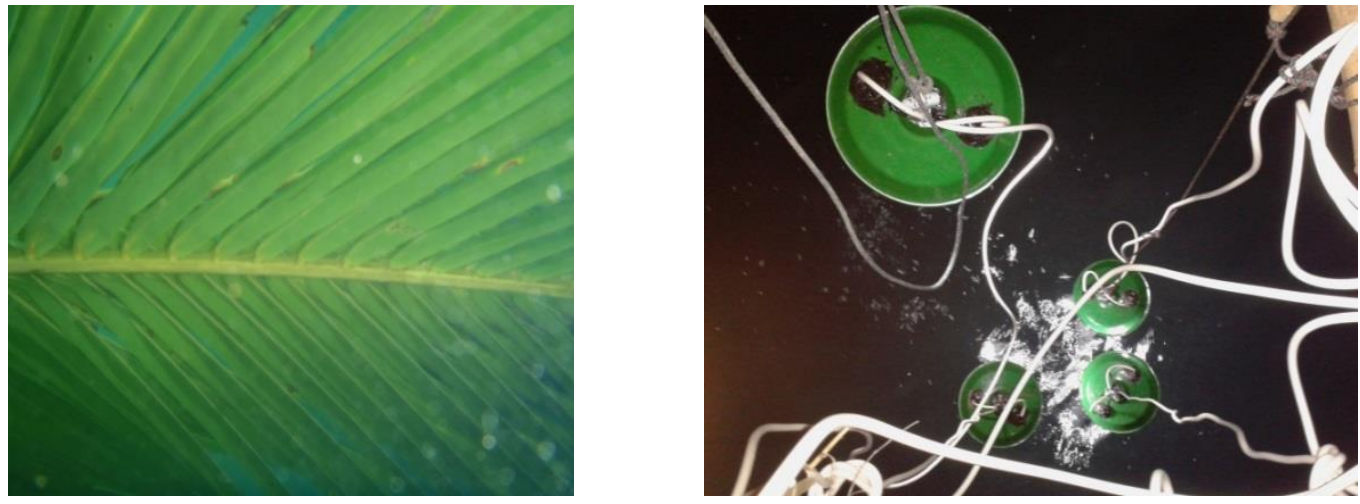

Gambar 2 Atraktor daun kelapa pada rumpon portable dan lampu setting LED

3) Perahu nelayan

Perahu nelayan yang digunakan adalah jukung. perahu tanpa mesin, menggunakan dayung sebagai alat untuk mengoperasikannya. Perahu tersebut digunakan untuk mengantar nelayan ke tempat pengoperasian bagan tancap. Untuk mengantarkan hasil tangkapan ke tempat pelelangan ikan (TPI) biasanya nelayan menggunakan perahu motor tempel 12 PK dengan panjang $\mathrm{x}$ lebar $\mathrm{x}$ dalam masing masing $7 \mathrm{~m} \mathrm{x} \mathrm{1,5} \mathrm{m} \mathrm{x} 1 \mathrm{~m}$.

4) Timbangan

Timbangan yang digunakan masing masing satu unit di setiap bagan, berat maksimum skala timbangan adalah $2 \mathrm{~kg}$.

5) Meteran digunakan untuk mengukur panjang ikan.

6) Kamera foto digital digunakan untuk dokumentasi selama penelitian.

7) GPS garmin

8) Echosunder

Pengukuran iluminasi cahaya dilakukan terhadap bagan A dengan lampu LED, posisi pengukuran lampu di lapangan diilakukan dengan tiga tahap:

1) Tengah adalah pusat dimana lampu operasi penangkapan diletakan

2) Diagonal 1 berjarak $(2,47)$ meter dari pusat

3) Diagonal 2 berjarak $(2,47)$ meter dari diagonal 1.

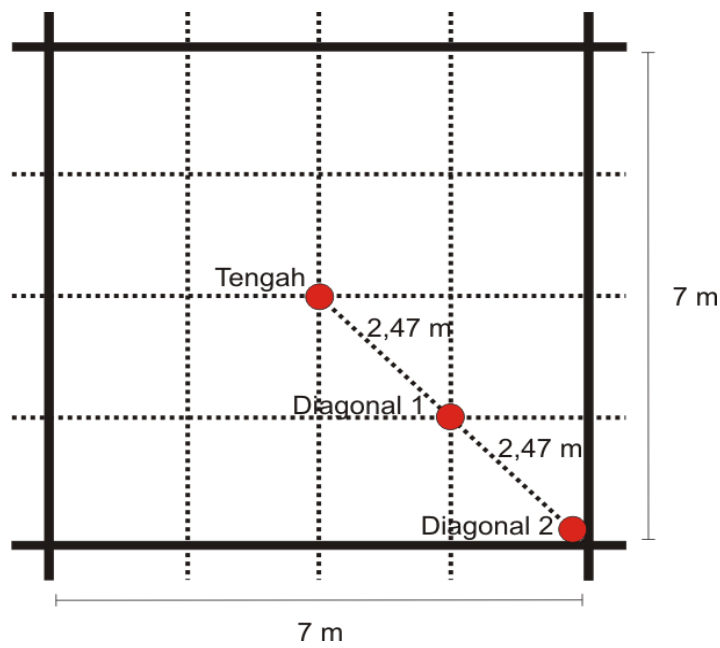

Gambar 3 pengukuran iluminasi tampak atas. 
Listrik yang digunakan dalam penelitian ini bersumber dari genset, untuk menstabilkan cahaya lampu yang digunakan maka diperlukan stabilizer, selanjutnya stop contact digunakan untuk menyambungkan listrik dari stabilizer menuju Magnetic Sircuit Bracker (MCB), selanjutnya listrik dialirkan kedua buah sakelar lampu hauling dan setting.

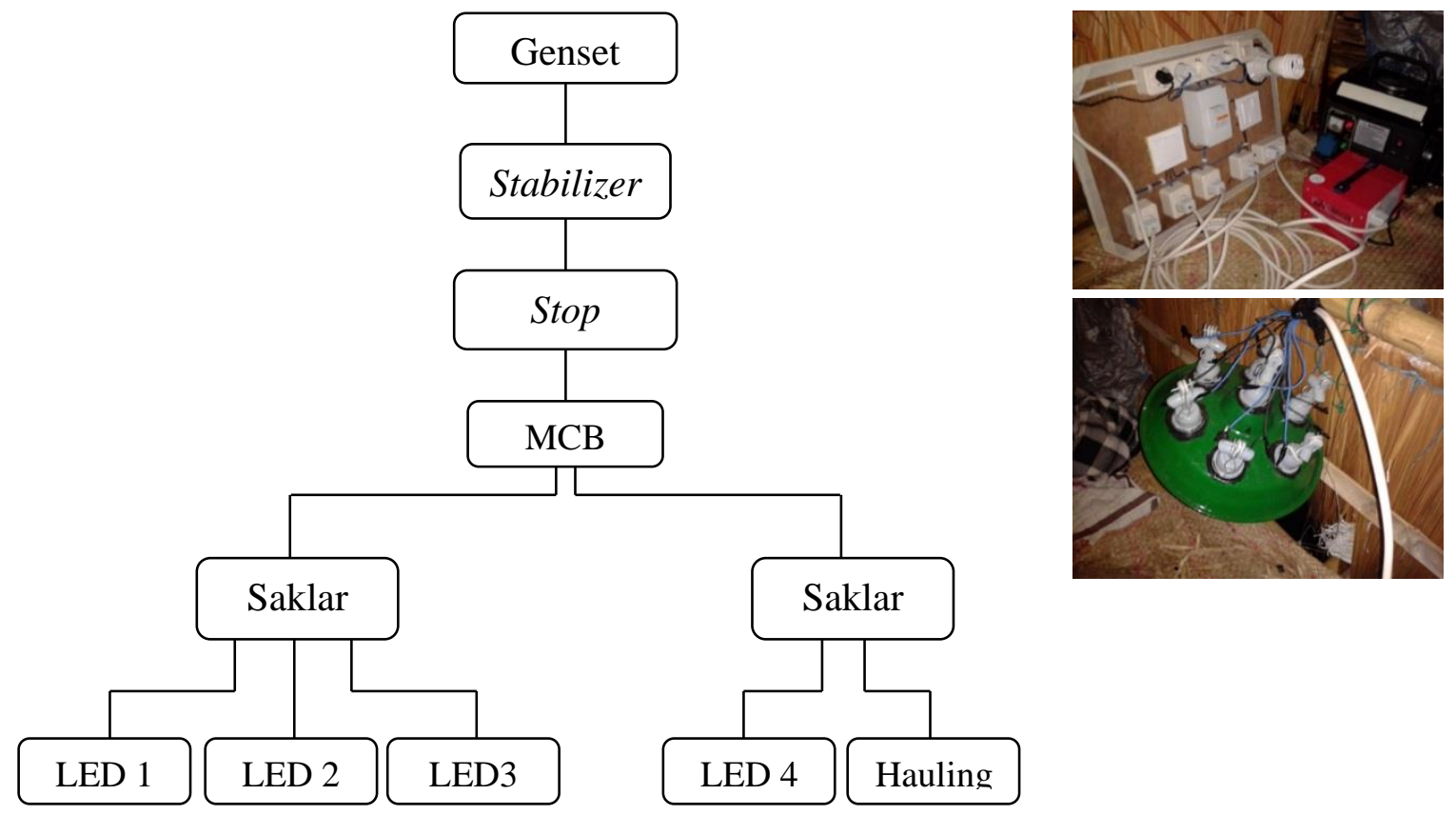

Gambar 4 Alir arus listrik yang digunakan pada penelitian

Penelitian ini merupakan uji coba penangkapan ikan (experimental fishing), membandingkan hasil tangkapan dan alat tangkap bagan dengan menggunakan rumpon portable dan lampu LED sebagai alat bantu. Penelitian ini dilakukan dengan ulangan 20 trip untuk setiap bagan. Data yang dikumpulkan merupakan data primer dan sekunder. Data primer diperoleh dengan cara mengikuti operasi penangkapan bagan dan melakukan pengamatan langsung terhadap pengaruh penggunaan lampu setting dan hauling pada bagan tancap.

Analisis data yang dilakukan pada penelitian ini adalah:

1) Analisis deskriptif

Data hasil tangkapan disajikan dalam bentuk tabel, kemudian dianalisis secara deskriptif menurut pokok-pokok bahasan sebagai berikut: (1) komposisi hasil tangkapan per jenis ikan; (2) hasil tangkapan (kg) per trip; (3) hasil tangkapan rata-rata (kg/hauling) per trip; (4) laju akumulasi ikan

2) Uji statistik

(a) Analisis ini akan dilakukan terhadap data dari bagan A dan B karena kedua bagan tersebut menggunakan rumpon dengan jumlah yang sama (4 unit) dan dioperasikan di tempat yang berdekatan. Metode statistika yang digunakan untuk menguji pengaruh jenis lampu adalah uji t dengan hipotesis sebagai berikut:

Ho: Hasil tangkapan per trip bagan A dan bagan B adalah tidak berbeda.

H1: Hasil tangkapan per trip bagan A dan bagan B adalah berbeda.

Analisis dilakukan pada taraf $\alpha=0,05$.

Jumlah ulangan $(n)=20$.

(b) Uji t juga digunakan pada bagan B dan C karena kedua bagan tersebut menggunakan lampu yang sama Flurescent lamp dan dioprasikan di tempat yang berdekatan dengan hipotesis sebagai berikut:

Ho: Hasil tangkapan per trip bagan $\mathrm{B}$ dan bagan $\mathrm{C}$ adalah tidak berbeda.

H1: Hasil tangkapan per trip bagan B dan bagan $\mathrm{C}$ adalah berbeda. 
Analisis dilakukan pada taraf $\alpha=0,05$.

Jumlah ulangan $(\mathrm{n})=20$.

$$
\text { nilai t dihitung sbb : } \quad \mathrm{t}=\frac{\left(\bar{x}_{1}-\bar{x}_{2}\right)-d_{0}}{\operatorname{sp} \sqrt{\left(\frac{1}{n_{1}}\right)+\left(\frac{1}{n_{2}}\right)}}
$$

\section{HASIL DAN PEMBAHASAN}

\section{Iluminasi Cahaya}

Berdasarkan hasil penelitian terhadap pengukuran iluminasi cahaya lampu LED. Sebaran nilai iluminasi akan menentukan posisi keberadaan wilayah berkumpulnya ikan. Menurut Zulkarnain (2002) dari hasil pengukuran iluminasi cahaya dapat diketahui dapat diketahui lapisan lapisan perairan yang disukai oleh ikan. Kedalaman 5-20 meter dengan nilai iluminasi 0,5-4 lux adalah daerah yang disukai oleh ikan. Dengan demikian pada penelitian ini nilai 0,5-4 lux berada pada diagonal 2 atau sudut dari bagan tancap karena daerar tersebut memiliki nilai iluminasi cukup rendah atau memiliki cahaya lampu remang remang. Hal ini membuktikan nilai intensitas cahaya yang digunakan oleh lampu hauling rendah disukai oleh ikan.

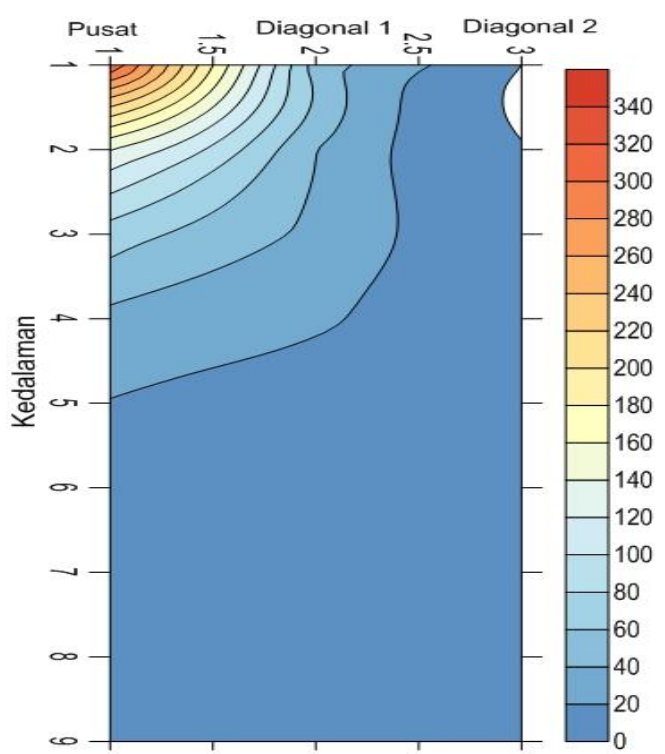

(A)

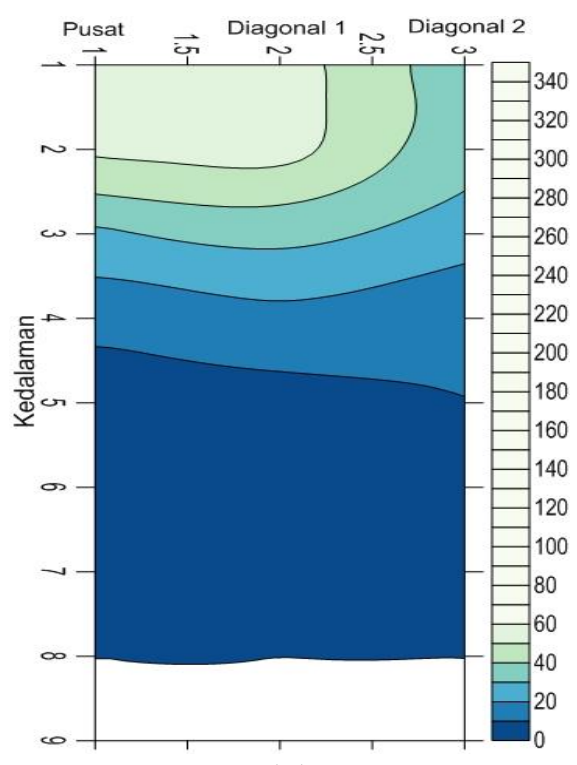

(B)

Gambar 5 Perbandingan kontur iluminasi cahaya bagan. (A) dengan lampu LED 60 watt, (B) dengan lampu spiral flurescent 24 watt.

Berdasarkan hasil penelitian di lapangan, sebaran iluminasi cahaya menunjukan bahwa adanya penaikan dan penurunan nilai iluminasi di setiap kedalaman yang berbeda. Penurunan nilai iluminasi cahaya terjadi pada setiap penurunan kedalaman, untuk kedalaman 1 meter dari bagian tengah sampai sudut diagonal bagan apung mengalami penurunan (200 lux, 30 lux, 0 lux), 2 meter (140 lux, 40 lux, 1 lux), dan seterusnya mengalami penurunan di setiap penambahan kedalaman, sedangkan untuk pengukuran iluminasi di setiap titik vertikal mengalami penaikan dan penurunan nilai iluminasi, untuk tengah atau pusat bagan dari kedalaman 0-1 meter mengalami penaikan nilai lux (200-320 lux), 1-2 meter mengalami penurunan nilai iluminasi (320-140 lux), dan sterusnya di setiap penambahan kedalaman mengalami penurunan nilai iluminasi. 
Lampu Setting (LED)

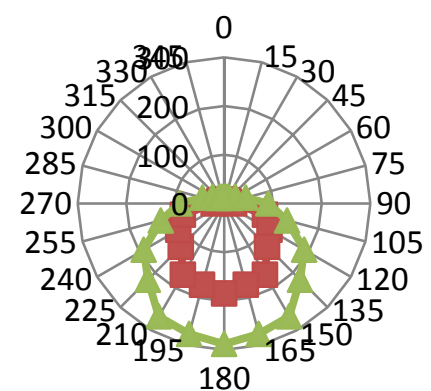

(A)

\section{Iluminasi Lampu hauling}

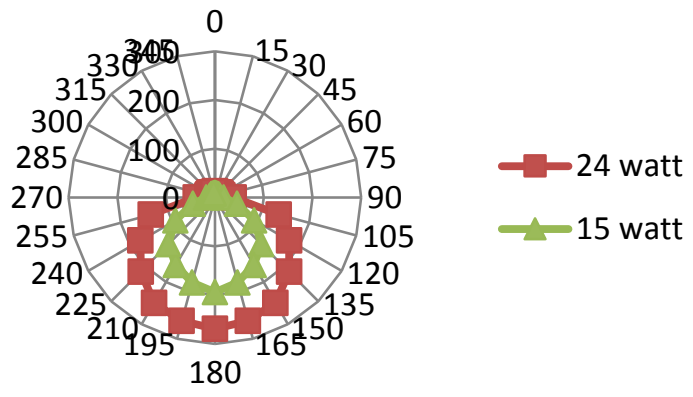

(B)

Gambar 6 Pengukuran cahaya lampu setting (A) dan lampu hauling (B) dengan menggunakan lux meter.

Pengukuran cahaya lampu LED dengan menggunakan lux meter. lampu LED yang digunakan pada penelitian dilapangan berjumlah 2 buah dalam 1 tudung. Pengukuran iluminasi cahaya dilakukan dengan jarak 1 meter dan diukur setiap penambahan sudut 15 derajat dari sumber cahaya. Terjadi kenaikan dan penurunan pada saat pengukuran iluminasi cahaya. Penurunan terjadi pada sudut 15 derajat (7 lux), 30 derajat (6 lux), sedangkan dari sudut 30 derajat sampai 180 mengalami peningkatan nilai iluminasi, pada 1 lampu didapatkan nilai iluminasi paling tinggi pada sudut 180 derajat (184). Sedangkan untuk 2 lampu dalam 1 tudung terjadi kenaikan nilai iluminasi disetiap penambahan sudut. 0 derajat (14 lux), 180 derajat (288).

Pengukuran iluminasi cahaya pada lampu hauling menunjukan kenaikan dan penurunan nilai iluminasi. Penurunan terjai pada lampu hauling 15 watt 0 derajat (10 lux), 15 derajat (9 lux). Nilai tertinggi berada pada sudut 180 derajat (135 lux). Sama seperti lampu hauling 15 watt, untuk lampu hauling 45 watt mengalami penaikan dan penurunan. Pada penelitian dilapangan nilai paling tinggi terdapat pada sudut 180 derajat (215 lux).

\section{Hasil Tangkapan Bagan Penelitian secara Keseluruhan}

Hasil tangkapan dari pengoperasian 3 bagan penelitian (masing-masing 20 trip), telah diperoleh 2.575,9 kg ikan yang terdiri dari 37 jenis. Lima jenis ikan yang paling banyak tertangkap selama penelitian adalah pepetek $(653,5 \mathrm{~kg}, 31,8 \%)$, udang rebon $(328,75 \mathrm{~kg}, 24,2 \%)$, tembang $(167,6$ $\mathrm{kg}, 6,5 \%)$, teri $(142,05 \mathrm{~kg}, 9,7 \%)$, dan layur (127,1 kg, 5,9\%). Sepuluh jenis ikan tertangkap kurang dari $10 \mathrm{~kg}$.
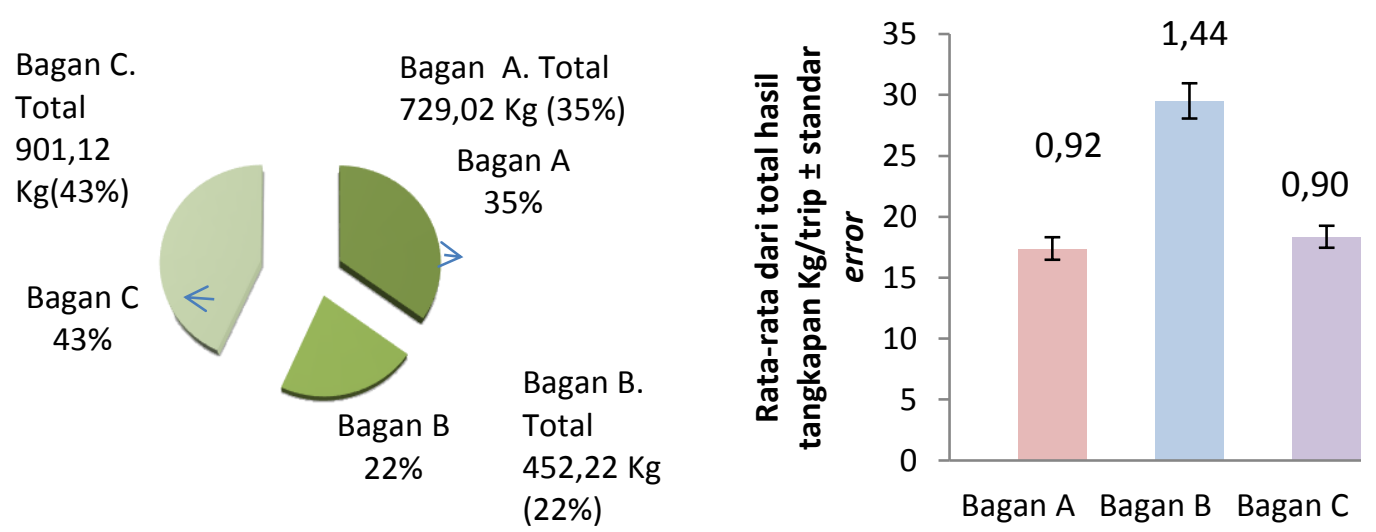

Gambar 7 Total dan rata-rata hasil tangkapan bagan A, B dan C 
Persentasi total hasil tangkapan tiga bagan penelitian selama 20 trip, bagan A mendapatkan 729,02 Kg (35\%), bagan B 452,22 Kg (22\%) dan bagan C 901,12 Kg (43\%). Pada penelitian ini bagan C mendapatkan persentasi paling tinggi sebesar $43 \%$ bagan A 35\% dan Bagan B 22\%, hali ini dikernakan lokasi bagan penelitian $\mathrm{C}$ lebih jauh dari garis pantai dan kedalaman perairan lebih dalam dari bagan B dan $\mathrm{A}$.

Tabel 1 Lima jenis ikan terbanyak ditangkap oleh bagan penelitian di Palabuhanratu, dalam periode Juli s.d. Agustus 2012.

\begin{tabular}{clccc}
\hline No & Nama local & Bagan A (Kg) & Bagan B (Kg) & Bagan C (Kg) \\
\hline 1 & Pepetek & 177,6 & 367,1 & 108,8 \\
2 & Udang rebon & 125,7 & 165,4 & 37,7 \\
3 & Teri & 17,5 & 51,9 & 72,7 \\
4 & Tembang & 52,3 & 26,5 & 88,9 \\
5 & Layur & 37 & 44,6 & 45,5 \\
\hline
\end{tabular}

Tabel 2 Hasil tangkapan rata-rata per trip \pm SE dari lima jenis ikan terbanyak ditangkap oleh bagan penelitian di Palabuhanratu, dalam periode Juli s.d. Agustus 2012.

\begin{tabular}{clccc}
\hline No & Nama local & Bagan A & Bagan B & Bagan C \\
\hline 1 & Pepetek & $6.5 \pm 0,42$ & $18,4 \pm 1,39$ & $5,7 \pm 0,25$ \\
2 & Udang rebon & $1,3 \pm 0,16$ & $2,6 \pm 0,34$ & $4,0 \pm 0,35$ \\
3 & Teri & $13,8 \pm 0,81$ & $11,1 \pm 0,75$ & $3,6 \pm 0,21$ \\
4 & Tembang & $0,5 \pm 0,09$ & $1,3 \pm 0,17$ & $4,5 \pm 0,84$ \\
5 & Layur & $1,9 \pm 0,18$ & $1,4 \pm 0,13$ & $2,3 \pm 0,20$ \\
\hline
\end{tabular}

Gambar 8 merupakan rata-rata hasil tangkapan \pm standar error dari masing-masing hasil tangkapan. Menurut uji statistik karena garis standar error antara hasil tangkapan ikan pepetek bagan $\mathrm{A}, \mathrm{B}$ dan $\mathrm{C}$ tidak bersinggungan maka hasil tangkpan ikan pepetek berbeda nyata. Begitu pula seterusnya untuk ikan teri, udang rebon, tembang dan layur, garis standar error antara hasil tangkapan bagan A,B dan $\mathrm{C}$ tidak bersinggungan maka hasil tangkapan ikan teri, udang rebon, tembang dan layur berbeda nyata.

Berdasarkan uji t statistik, diketahui bahwa hasil tangkapan yang berpengaruh terhadap perbedaan jenis lampu adalah udang rebon, teri dan layur. Hal tersebut sesuai dengan pernyataan subani dan barus (1972), bahwa ketiga ikan tersebut termasuk kedalam kelompok ikan fototaksis positif. Dari kelima jenis ikan hasil tangkapan yang paling banyak tertangkap di bagan A dan B, ikan tembang adalah ikan yang paling banyak tertangkap pada bagan A, sedangkan keempat ikan lainya paling banyak tertangkap pada bagan B. Berdasarkan hasil uji statistik total hasil tangkapan Bagan A dan Bagan B didapatkan nilai $\mathrm{t}$ hitung -1,89 Dan $\mathrm{t}$ tabel 1,72. Hal tersebut menunjukkan $\mathrm{t}$ hit $<\mathrm{t}$ tabel, pada tingkat tingkat kepercayaan $95 \%$. sehingga total hasil tangkapan bagan A dan B tidak berbeda nyata.

Sedangkan untuk perbedaan jenis rumpon yang digunakan pada bagan B dan C berdasarkan hasil uji t statistik t hitung 1,74 dan t tabel 1,72 t hitung > dari t tabel. Pada selang kepercayaan 95\% jika $\mathrm{t}$ hitung $>\mathrm{t}$ tabel maka hasil tangkapan bagan $\mathrm{B}$ dan $\mathrm{C}$ berbeda nyata.

Berdasarkan uji t statistik, diketahui bahwa perbedaan penggunaan jenis lampu pada bagan tidak memberikan pengaruh terhadap jumlah hasil tangkapan ikan pepetek. Nilai signifikansi antara jumalh hasil tangkapan pepetek dengan penggunaan jenis lampu yang berbeda adalah 0,001. Nilai tersebut kurang dari nilai taraf $\alpha 0,05$. 

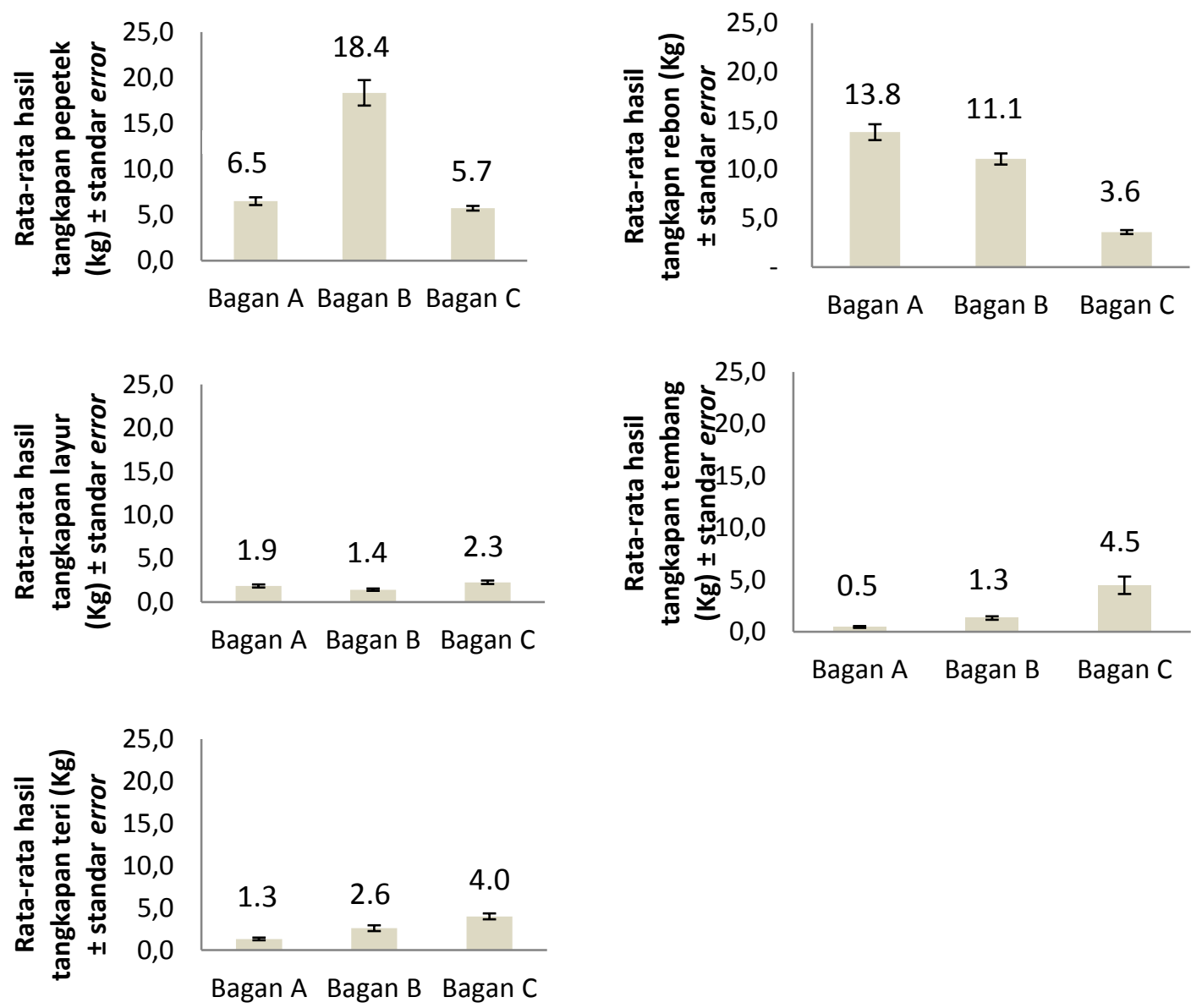

Gambar 8. Rata-rata hasil tangkapan lima jenis ikan dominan tertangkap dengan standar error

Berdasarkan uji statistik pada hasil tangkapan udang rebon, diketahui pengaruh perbedaan jenis lampu pada bagan A dan B memberikan pengaruh terhadap jumlah hasil tangkapan.. Nilai signifikansi antara jumlah hasil tangkapan udang rebon adalah 0,282. Nilai tersebut lebih dari nilai taraf $\alpha 0,05$.

Penggunaan jenis lampu yang berbeda pada bagan memberikan pengaruh yang berbeda terhadap jumlah hasil tangkapan teri. Hal tersebut ditunjukan oleh hasil uji t statistik, dimana nilai signifikansi antara jumlah hasil tangkapan teri dengan penggunaan jenis lampu yang berbeda adalah 0,213. Nilai tersebut lebih dari nilai taraf $\alpha 0,05$.

Penggunaan jenis lampu yang berbeda pada bagan tidak memberikan pengaruh yang tidak berbeda terhadap jumlah hasil tangkapan tembang. Hal tersebut ditunjukan oleh nilai uji t statistik, dimana nilai signifikansi antara jumlah hasil tangkapan tembang dengan lampu yang berbeda adalah 0,035. Nilai tersebut lebih dari nilai taraf $\alpha 0,05$. penggunaan jenis lampu yang berbeda mempengaruhi jumlah hasil tangkapan layur. Nilai signifikansi antara jumlah hasil tangkapan layur adalah 0,980. Nilai tersebut lebih dari nilai taraf $\alpha 0,05$.

Berdasarkan uji t statistik, diketahui bahwa untuk lima jenis ikan yang dominan tertangkap. Hasil tangkapan yang berpengaruh terhadap perbedaan jumlah rumpon yang dipasang adalah jenis ikan teri, tembang dan layur. Berdasarkan uji t statistik hasil tangkapan ikan teri, tembang dan layur pada Bagan B dan Bagan C didapatkan nilai t hitung berturut turut -1,26, -0,94, -0,74 Dan t table berturut turut 1,72,1,72, 1,72. Hal tersebut menunjukkan $\mathrm{t}$ hit $<\mathrm{t}$ tabel, pada tingkat selang kepercayaan 95 \%. sehingga total hasil tangkapan bagan B dan C berbeda nyata. Sedangkan untuk ikan reboan dan pepetek mendapatkan nilai t hitung berturut turut 1,40, 1,92 dan tabel berturut 
turut 2,09, 2,09. Hal ini menunjukan $\mathrm{t}$ hitung $>\mathrm{t}$ tabel pada tingkat selang kepercayaan 95\%, sehingga hasil tangkapan rebon dan pepetek di bagan B dan C tidak berbeda nyata. Semakin banyak rumpon yang dipasang maka untuk jenis ikan teri, tembang dan layur akan semakin banyak tertangkap.

\section{KESIMPULAN DAN SARAN}

\section{Kesimpulan}

Berdasarkan penelitian dilapangan, diketahui bahwa hasil tangkapan yang berpengaruh terhadap perbedaan jenis lampu (LED) adalah udang rebon, teri dan layur, ketiga ikan tersebut termasuk kedalam kelompok ikan fototaksis positif. Dari kelima jenis ikan hasil tangkapan yang paling banyak tertangkap di bagan A dan B.

Persentasi total hasil tangkapan tiga bagan penelitian selama 20 trip, bagan A mendapatkan $729,02 \mathrm{Kg}(35 \%)$, bagan B 452,22 Kg (22\%) dan bagan C 901,12 Kg (43\%). Pada penelitian ini bagan C mendapatkan persentasi paling tinggi sebesar $43 \%$ bagan A 35\% dan Bagan B 22\%, hali ini dikernakan lokasi bagan penelitian $\mathrm{C}$ lebih jauh dari garis pantai dan kedalaman perairan lebih dalam dari bagan B dan A.

Hasil tangkapan dari pengoperasian 3 bagan penelitian (masing-masing 20 trip), telah diperoleh $2.575,9 \mathrm{~kg}$ ikan yang terdiri dari 37 jenis. Lima jenis ikan yang paling banyak tertangkap selama penelitian adalah pepetk $(653,5 \mathrm{~kg}, 31,8 \%)$, udang rebon $(328,75 \mathrm{~kg}, 24,2 \%)$, tembang $(167,6$ $\mathrm{kg}, 6,5 \%)$, teri $(142,05 \mathrm{~kg}, 9,7 \%)$, dan layur $(127,1 \mathrm{~kg}, 5,9 \%)$. Sepuluh jenis ikan tertangkap kurang dari $10 \mathrm{~kg}$.

Saran

Perlu ada penelitian lebih lanjut dengan menggunakan metode observasi bawah air untuk mengetahui jenis ikan yang berakumulasi di rumpon secara visual.

\section{DAFTAR PUSTAKA}

Ben Yami. 1987. Fishing With Light. Roma : FAO

Ben Yami. 1988. Attracting Fishing With Light. Roma : FAO

Effendi M. 1997. Biologi Perikanan. Yogyakarta : Yayasan Perpustakaan Nusantara.

Gunarso. 1988. Tingkah Laku Ikan dalam Hubunganya dengan Alat, Metoda, dan Teknik Penangkapan. Bogor : Fakultas Perikanan. Institut Pertanian Bogor.

Nikolsky GV.1963. The Technologi of Fishes. London : Academic press.

Subani W, H R Barus. 1989. Alat tangkap Ikan dan Udang Laut di Indonesia. Jurnal Penelitian Perikanan Laut No.50 tahun 1989. Balai Penelitian Perikanan Laut

Zulkarnain. 2002. Studi Tentang Penggunaan Rumpon Pada Bagan Apung Di Teluk Palabuhanratu, Jawa Barat. [Tesis]. Bogor : Fakultas Perikaan dan Ilmu Kelautan. Institut Pertanian Bogor. 